Health \& Medicine | Bettina Ryll, Gilliosa Spurrier \& Violeta Astratinei

V2A2

A tool to promote patient agency through effective patient information

\begin{tabular}{|c|c|c|}
\hline $\begin{array}{l}\text { The Melanoma Patient } \\
\text { Network Europe (MPNE) } \\
\text { attaches particular importance } \\
\text { to effective scientific patient } \\
\text { information. As a patient } \\
\text { community with a keen } \\
\text { research interest, the network } \\
\text { has over the years developed } \\
\text { its own methodology and } \\
\text { standards on how to rapidly } \\
\text { and accurately share scientific } \\
\text { information even across } \\
\text { language boundaries. Bettina } \\
\text { Ryll, Gilliosa Spurrier and } \\
\text { Violeta Astratinei, founders of } \\
\text { MPNE, have developed the } \\
\text { tool V2A2, hoping it will be } \\
\text { of use to all those passionate } \\
\text { about effective educational } \\
\text { content for patients and } \\
\text { patients advocates. }\end{array}$ & $\begin{array}{l}\text { he Melanoma Patient Network } \\
\text { Europe, MPNE, is a network of } \\
\text { European Melanoma patients and } \\
\text { their family members. Melanoma has seen } \\
\text { significant therapeutic progress in the } \\
\text { last decade, from a situation of median } \\
\text { survival of } 69 \text { months to about half of } \\
\text { all patients with advanced Melanoma } \\
\text { now surviving the disease. In a rapidlly } \\
\text { evolving treatment landscape, education } \\
\text { about new treatment options including } \\
\text { clinical trials was and remains critical for } \\
\text { the patient community. As unfortunately } \\
\text { still too many Melanoma patients die, } \\
\text { research remains an important focus area } \\
\text { of the network. Research engagement } \\
\text { - be it the selection of a clinical trial, } \\
\text { the review of clinical trial designs or } \\
\text { research protocols, or the drafting of } \\
\text { project proposals - requires a high } \\
\text { level of scientific understanding. MPNE } \\
\text { therefore places particular importance } \\
\text { on scientific education and has over the } \\
\text { years developed its own methodology } \\
\text { to rapidly and accurately disseminate } \\
\text { relevant research findings across } \\
\text { its network. For example, scientific } \\
\text { information on any of MPNE's patient } \\
\text { forums needs to be referenced and the } \\
\text { network provides continuous training on } \\
\text { how to access and read scientific articles. } \\
\text { MPNE's ultimate aim is to increase } \\
\text { what the advocates themselves refer } \\
\text { to patients' agency, the ability to make } \\
\text { informed decisions regarding their own } \\
\text { health. Bettina clarifies: "We prefer the } \\
\text { concept of agency over the more } \\
\text { commonly used'patient } \\
\text { empowerment' because } \\
\text { of its directionality: the } \\
\text { actor is the patient. } \\
\text { Patientempowerment } \\
\text { assumes a helpless patient } \\
\text { waiting to be empowered by } \\
\text { a benevolent outsider. Agency } \\
\text { describes an autonomous patient } \\
\text { assuming responsibility and taking } \\
\text { action." }\end{array}$ & $\begin{array}{l}\text { V2A2: CODIFYING EDUCATIONAL } \\
\text { CULTURE IN A TOOL } \\
\text { In } 2018 \text {, MPNE joined Share4Rare, a } \\
\text { project funded by the European Union } \\
\text { with the aim to facilitate data sharing } \\
\text { between patients in a secure and non- } \\
\text { commercial environment. Share4Rare's } \\
\text { managed research feature allows to } \\
\text { rapidly initiate research projects with } \\
\text { validated participants, ethics board } \\
\text { reviewed projects and advanced data } \\
\text { protection securing patients' best } \\
\text { interests. It quickly became apparent } \\
\text { that Share4Rare would require patients } \\
\text { to understand the value and importance } \\
\text { of research in order to engage - and } \\
\text { that MPNE's organically grown network } \\
\text { scientific culture would not be easily } \\
\text { transferable to a new community. } \\
\text { V2A2 therefore became MPNE's effort } \\
\text { to codify their learnings about what } \\
\text { constitutes effective patient information } \\
\text { in a scientific context as a multi-purpose } \\
\text { tool that could be used to either directly } \\
\text { review existing patient information } \\
\text { material or to educate about the } \\
\text { four domains that the advocates has } \\
\text { identified as highly relevant: validitity, } \\
\text { verifiability, accessibility and agency that } \\
\text { then became V2A2. } \\
\text { It is important to note that validity and } \\
\text { verifiability ytand in natural tension to } \\
\text { accessibility on one and agency on the } \\
\text { other side and therefore need to be } \\
\text { carefully balanced for optimal results. } \\
\text { For example, in the desire to create } \\
\text { accessible content, an author might be } \\
\text { tempted to omit technical terms and } \\
\text { references. Technical terms are vital } \\
\text { to searching for correct information } \\
\text { and key to avoiding fake news while } \\
\text { omission of references prevents the } \\
\text { reader from verifying the trustworthiness } \\
\text { of the information, ultimately limiting } \\
\text { agency. In contrast, a highly referenced } \\
\text { text might be easily verifiable, but often }\end{array}$ \\
\hline
\end{tabular}
negatively affects readability. This in
turn reduces the accessibility of the text curtailing agency yet again.

\section{TOOL DEVELOPMENT}

In addition to the documentation and a V2A2 user guide, V2A2 consists of given text is rated. Items are scored for presence or absence and positive rating summarised, with a high score out of 20 indicating a well-written patient information text. MPNE now uses the tool to self-evaluate the educational content it produces. If consistent results are required, they recommend several (3-5) parallel and independen evaluations, followed by a comparative analysis as certain items contain a degree of subjectivity. Overall, V2A2 is intended as a guide, not as an absolute measure and has proven equally useful as an educational tool to illustrate factors the educational value for patients.

V2A2 v1.0 was developed by Bettina Ryll, Gilliosa Spurrier and Violeta Astratinei, and user-tested during the annual network conference MPNE2019 in Brussels. Based on user feedback, V2A2 was amended to the current version (v1.1.) and the too complemented by the V2A2 userguide. V2A2 is covered by a CC BY SA (Creative Commons Attribution-Share Alike) licence and can be easily adapted for personal branding.

\section{V2A2 IN DETAILS}

V2A2's 20 items cover the four domains 4-9), accessibility (items 10-18) and agency (items 19-20).

\section{VALIDITY}

completeness and

accuracy, the validity of medical and scientific content is critically dependent on how recently the content was generated. All content therefore should be dated and reviewed regularly. Bettin suggests providing content with a "valid until date and the date of the prospectively scheduled next review, process facilitated by automation.

- Item 1: Is the content complete and accurate?

- Item 2: Is the content dated, both original and last review?

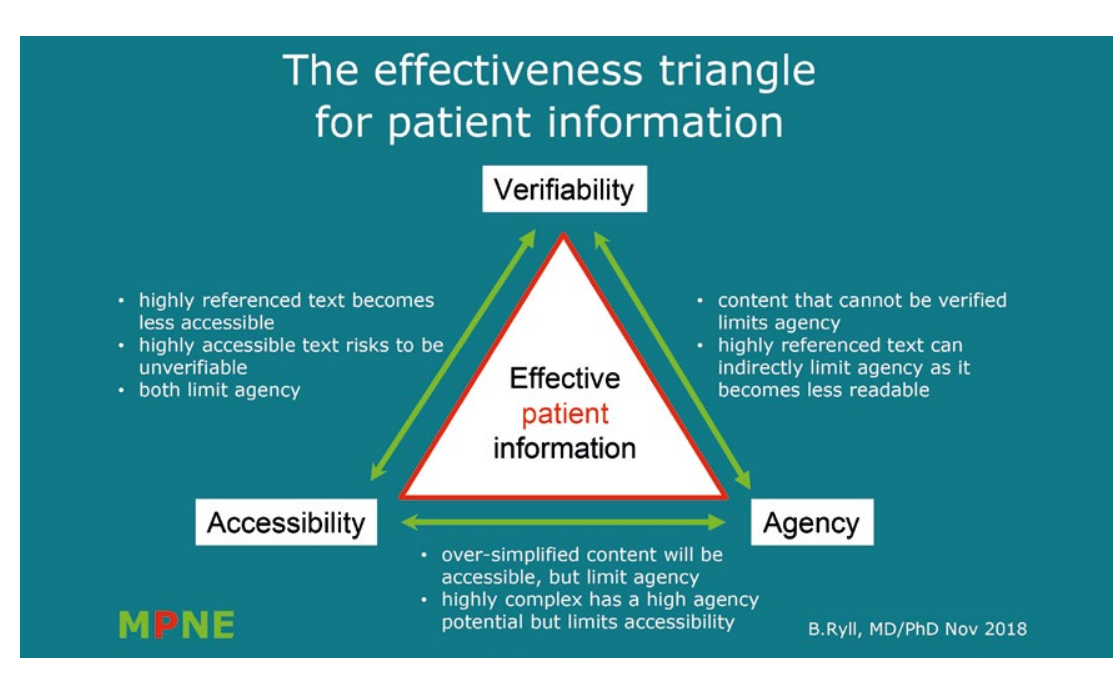

- Item 3: Is the next review date scheduled?

\section{VERIFIABILITY}

Content needs to be easily verifiable

independent verification Items

4-6 address whether claims are

appropriately referenced, eg citing

a correct and credible source and

stating how easily traceable it is. Ideally,

references should be provided as

of the scientific article as readers might

\section{ACCESSIBILITY}

The technical nature of scientific or medical publications poses considerable challenge for a lay aspects: the technicality of the lanses three general readability for factors knowag, affect the accessibility of a text and the overall structure as particularly relevant for web-based content. To verify the technicality of the language, items 10-12 examine whether all abbreviations are either replaced by the full-text version

The team prefers the concept of agency over 'patient empowerment' because of its directionality: the actor is the patient.

not be familiar with PubMed and are unlikely to have institutional access to the authorship of the article - cover should be identifiable by their full name provide credentio to their affiliation to an academic department and potential conflict of interests.

- Item 4: Are all claims supported by references?

- Item 5: Are the references valid? - Item 6: Are the references easy to trace?

- Item 7: Is the name of the author indicated, both for original and every review?

- Item 8: Are professional or other credentials of the author clearly stated?

- Item 9: Are there any potential conflicts of interest? then distinguishes between unnecessary technical jargon that should be removed be explained.

For example, 'the cancer metastasizes' can be replaced without loss of information by the more accessible 'the cancer spreads throughout the body'. In contrast, terms with relevance for prognosis, e.g. 'ulceration' in Melanoma, treatment decisions e.g. 'progression' or 'hypophysitis' under therapy with and not replaced as patients are likely to encounter them in their interaction with their medical team and awareness of the term greatly increases the likelihood of retrieving relevant information online.

- Item 10: Are all abbreviations explained? checkpoint inhibitors should be explained 


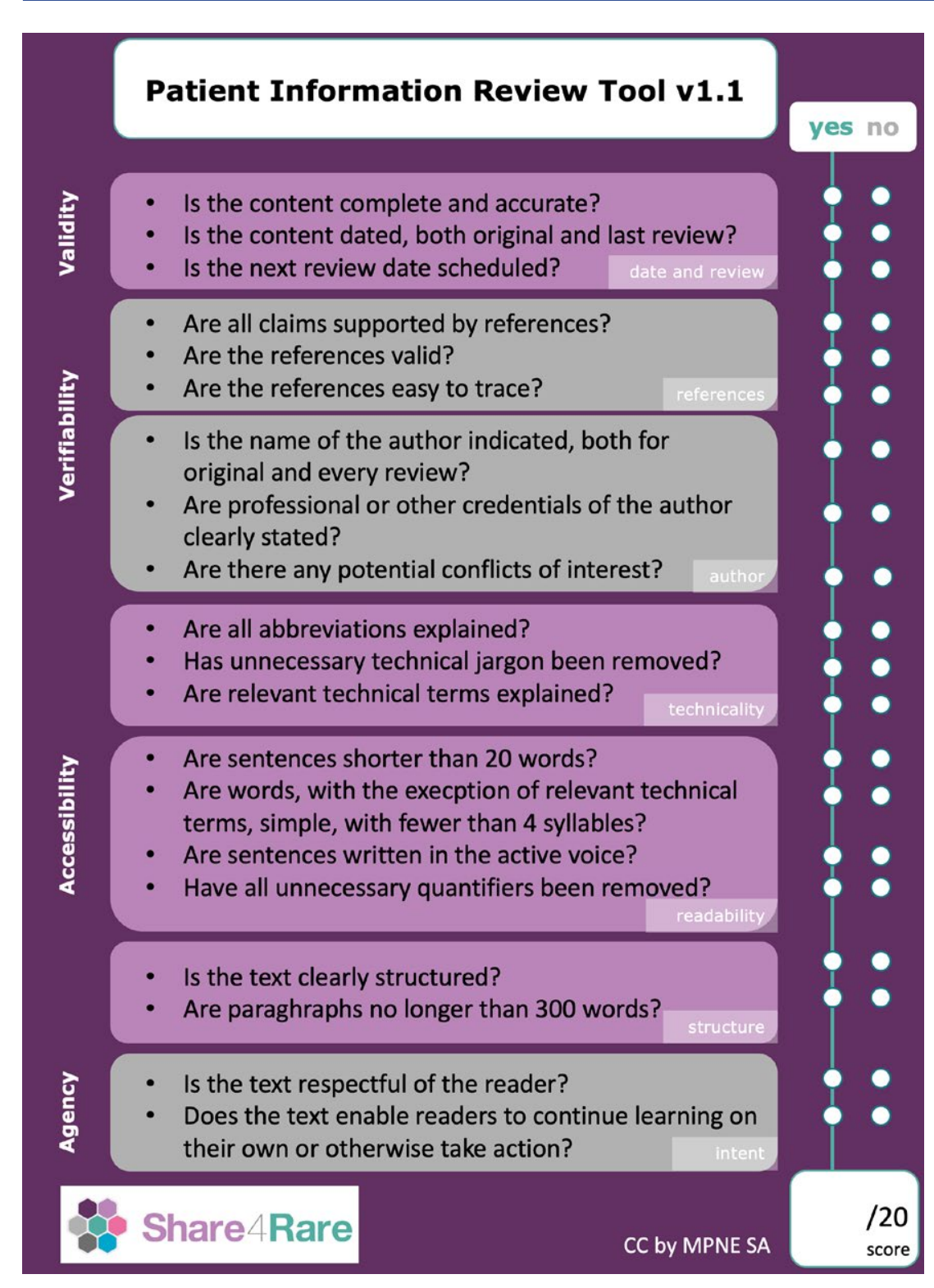

For patients, knowledge means protection and influence in research. Education is the key and V2A2 the accelerator to that knowledge.

- Item 11: Has unnecessary technical - Item 12: Are relevant technical terms explained?

tem 13-16 evaluate current ecommendations for increased readability such as the Readability Test Tool (https://www.webrx.com/tools/ read-able/, the Gunning Fog Index hittp://gunning-tog-index.com/ and hemingwayay App htep:/ / www. lemingwayapp.comn, including the
- Item 16: Have all unnecessary quantifiers been removed? As text structure contributes to the (t) skimming for relevant information, item 17-18 evaluate overall structure as well as paragraph length.

- Item 17: Is the text clearly structured? Item 18: Are paragraphs shorter than 300 words?

AGENCY

Provided content should increase

readers' agency and reflexivity, meaning

their capacity to define and shape their

(hin proftes, preferences and norms

(high reflexivity) instead of merely

are often written in a patronising or

infantilising tone which is disrespectf

and demoralising. Items 19-20 therefor

evaluate whether material is respectful

towards the readership as well as in

how far it encourages and facilitates

independent further learning as critical

factors for assuming agency.

- Item 19: Is the text respectful of the

readership?

- Item 20: Does the text allow readers to continue to learn on their own, take other action and does it increase ther range of options?

SHARE4RARE: SHARING TO HELP PATIENTS WITH RARE CONDITIONS After having seen the impact of

accessible scientific knowledge on their own network, the MPNE advocates are keen to share their learnings with the wider patient community. In particular. rare conditions who might not be so lucky to have a supportive community behind them. Violeta, founder of Melanom Romania, states: "For patients, knowledge means protection. Knowledge also means influence in research in your disease area. And education is the key and V2A2 the accelerator to that knowledge!" The advocates are now working towards the next goal: establishing a Share4Rare research plattorm that enables patient comn valides to intiate andrin the reflexivity). Texts directed at patients they want to help patients affected by

\section{Behind the Research}

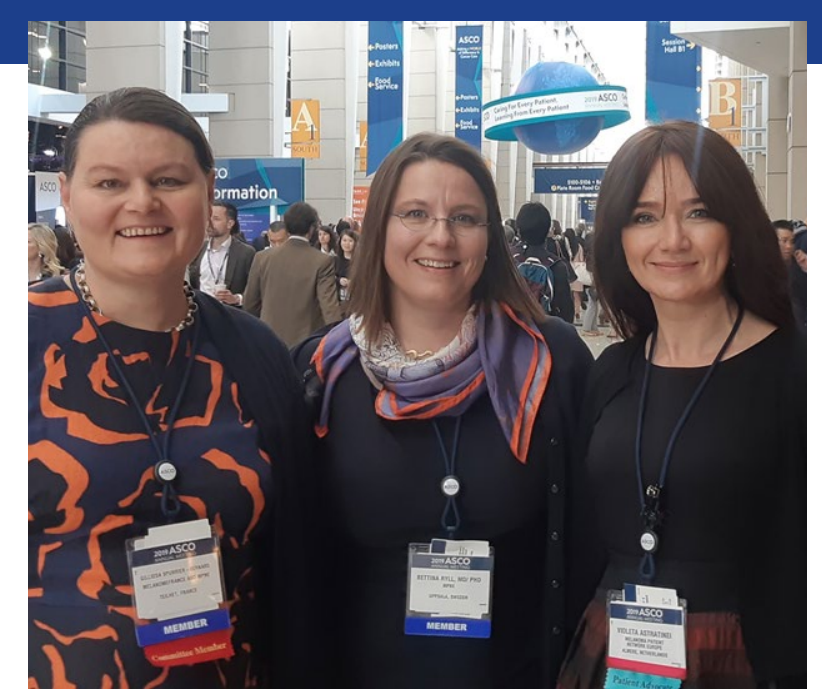

Detail

Bettina Ryll

Melanoma Patient Network Europe Fjällbo Selknä 152

75597 Uppsala, Swede

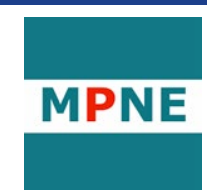

Bio

The Melanoma Patient Network Europe (MPNE) was founded in 2013 by Bettina Ryll. MPNE functions as an organically growing multi-dimensional network system that applies the diverse learnings - from gene networks over learning techniques to learn start-up principles -

Funding

This project has received funding from the European

greement No 780262

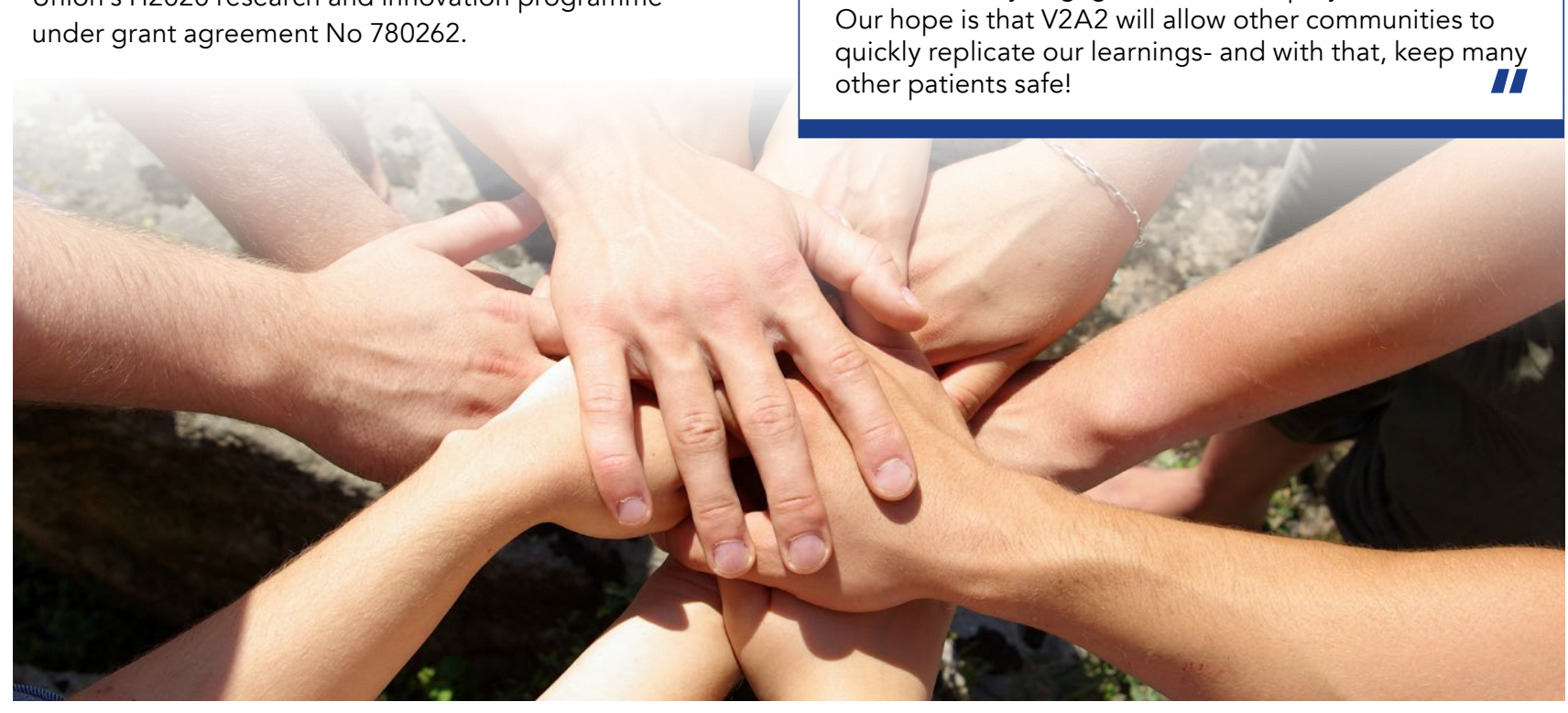

Gilliosa Spurrier

Violeta Astratine

E: bettina.ryll@mpneurope.org

W: violeta.astratinei@mpneurope.org

Research Objectives

MPNE are developing a user-friendly tool that helps promote patient agency by providing means to assess patient information

\section{References}

Share4Rare [online]. Available at: https://www.share4rare. org/ [Accessed 10/07/2020]

\section{Personal Response}

What inspired you to create V2A2?

II We have learned in Melanoma that knowledge keeping up to date ourselves and sharing scientific information via diverse patient forums and across language barriers. As a result, our forums have become safe places forle As a est our torums have become
Dr Bettina Ryll therefore spend considerable time and effort on
- Item 13: Ars
20 words? of relevant technical tems, fewer than 4 syllables?

15: Are sentences w active voice? 